\author{
Jakub Marszałkiewicz \\ $\mathrm{dr}$ \\ Wyższa Szkoła Bankowa w Gdańsku \\ jak.marszalkiewcz@gmail.com
}

DOI: 10.35117/A_ENG_17_12_01

\title{
The threat on airports from unmanned aerial vehicles
}

\begin{abstract}
This article provides a general overview of the threats on airports caused by widespread use of unmanned aerial vehicles (UAVs), commonly referred to as drones. They are increasingly available and can therefore be used as a means of unlawful interference against Critical Infrastructure, especially against airports. Also selected are examples of UAV applications for airport security and disturbance and anti-UAV systems.
\end{abstract}

Keywords: UAV; Unmanned aerial vehicle; Drone; Airport; Critical infrastructure

\section{Introduction}

The functioning of a civilized state depends on an efficient system that ensures citizens' life at an appropriate level. This system is generally referred to as Critical Infrastructure (IK). Act of April 26, 2007 on crisis management (Dz. U. No. 89, item 59o, with later d.) defines IK as systems and their functionally interconnected objects, including construction objects, devices, installations, key services for the security of the state and its citizens, and for ensuring the efficient functioning of public administration bodies, as well as institutions and entrepreneurs. Critical infrastructure includes the following systems: energy supply, energy raw materials, and fuels, communications, ICT networks, financial, food supply, water supply, healthcare, transport and rescue services, ensuring the continuity of public administration, production, storage, storage and use of substances chemical and radioactive, including pipelines of dangerous substances [19], [21]. From this description, it is clear that one of the main elements of CI is the transport and logistics system. It includes airports.

\section{The possibility of using UAV in a terrorist attack}

Easy accessibility UAV also has its bad sides. It causes, that the UAV is also increasingly used by criminals and terrorists. For example, armed units of the so-called The Islamic State has already been using UAV for some time, adapted by means of home-made methods for transferring armaments (especially light bombs, but also missiles). Initially, ISIS used commercial drones (eg DJI Phantom) temporarily equipped with explosive charges, but recently they learned to construct their own unmanned aircraft, both in the airframe (aircraft) and the multi-rotor powered-lift system. Particularly noteworthy is an amateur-built multi-gun equipped with an anti-tank rocket launcher. ISIS also uses the UAV in the form of a flying wing equipped with specially designed light bombs for this purpose. This aircraft is controlled by advanced software that allows precise target guidance. Terrorist on the current surprises the world with ingenuity and increasingly advanced warfare agents that they can create. Mastering their service and even the production of relatively advanced UAVs is very dangerous for transport infrastructure. This applies especially to seaports, airports and logistic bases located in restless areas. This is one of the factors that make the military-political instability of the Middle East and Africa seem to be the biggest threat to international transport in the 21 st century. 


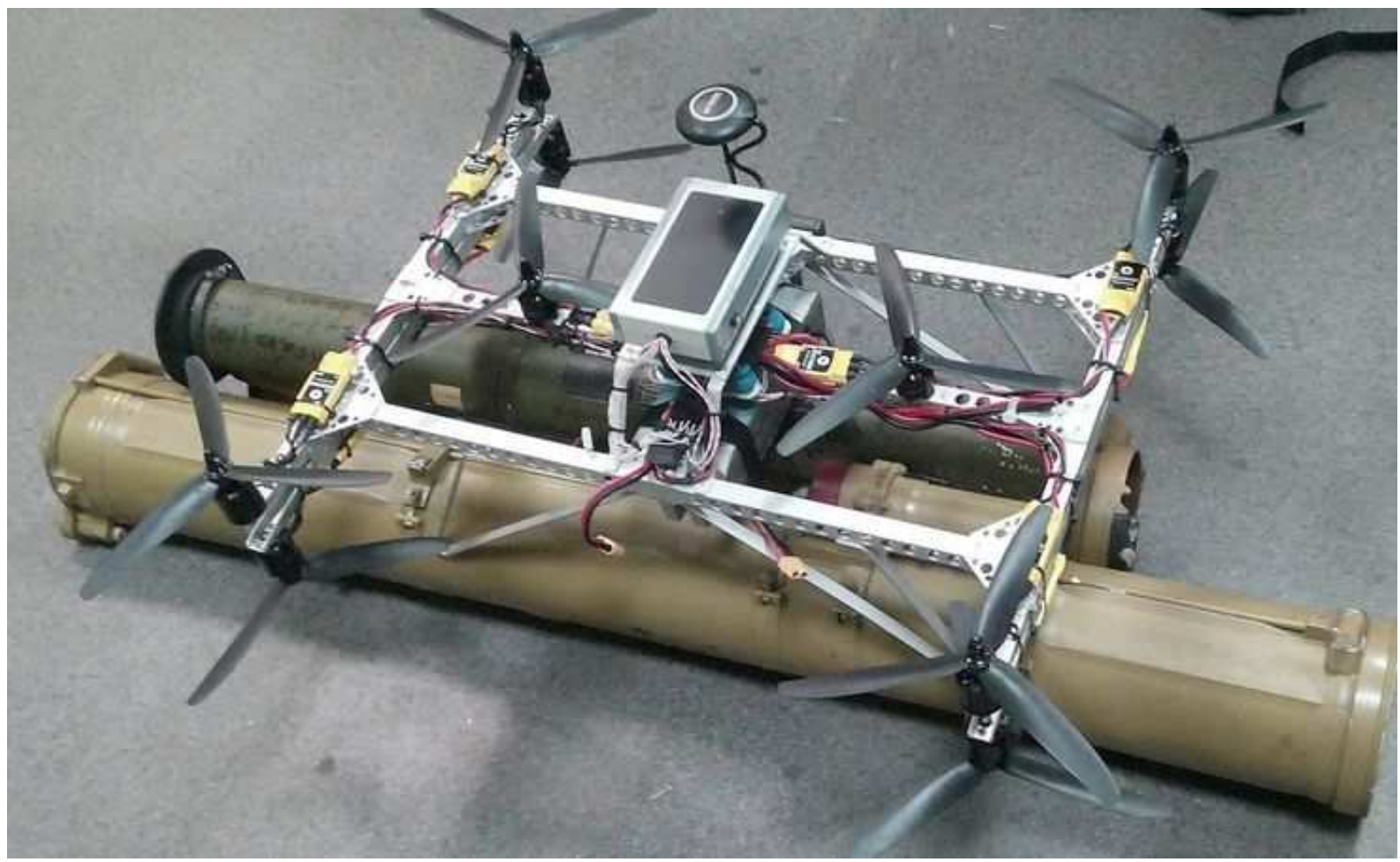

1. Amateur UAV armed with an anti-tank rocket launcher built by ISIS [14]

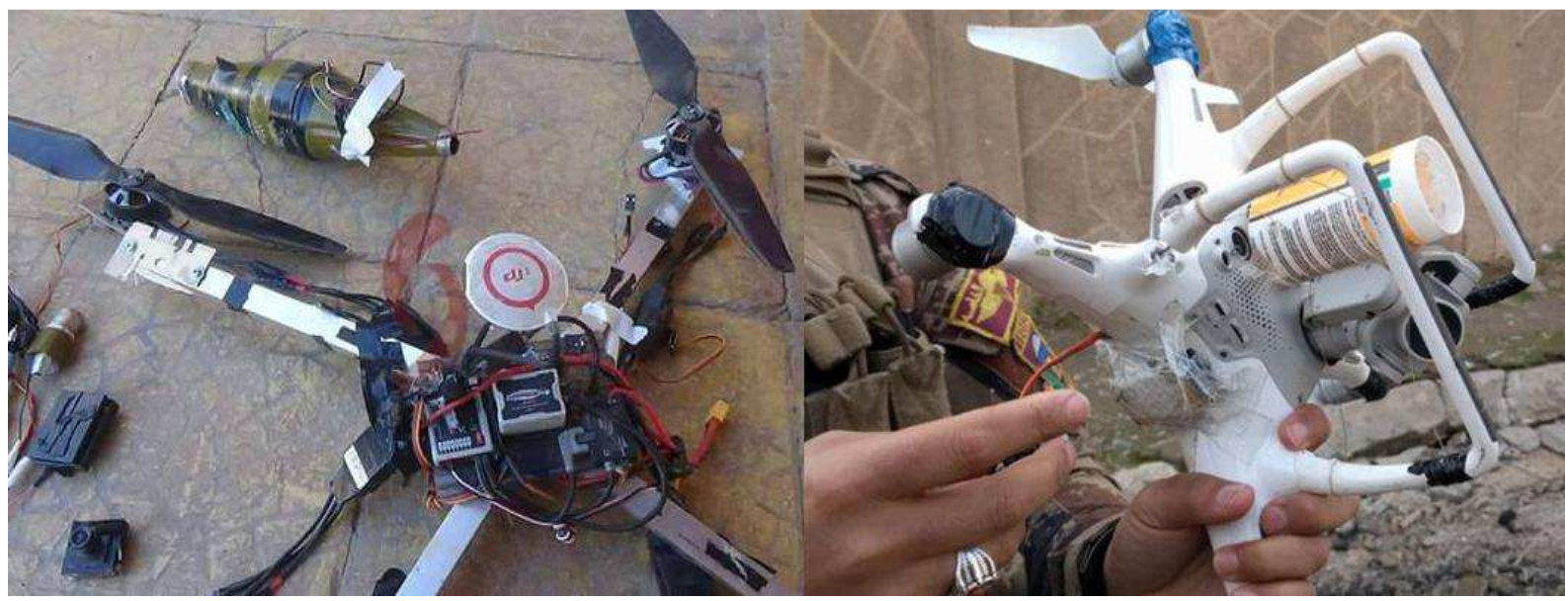

2. Battle drones constructed by ISIS: commercial Chinese DJI Phantom with attached explosive charge (top) and a flying wing bomber that can carry light homemade bombs [15]

This is a serious threat to the safety of airports and planes taking off and landing. Even the usual commercial drones used by irresponsible operators can threaten security. For example, on July 21, 2015, a small UAV appeared on Okęcie just 100 meters from communication airplanes. Although it was the first such incident in Poland, it is unfortunately not an exception. The world is registering more and more of such dangerous events with the use of civilian, private, low-cost unmanned vehicles, whose speed, range and ceiling, as well as payload, are increasing at relatively low costs of such platforms. Very similar to the Polish one, was an incident at Heathrow in December 2014, when the unmanned drone appeared within a dozen meters of the landing machine. Unidentified drones also landed on the 
premises of a nuclear power plant, military units or even in the gardens of the White House [4].

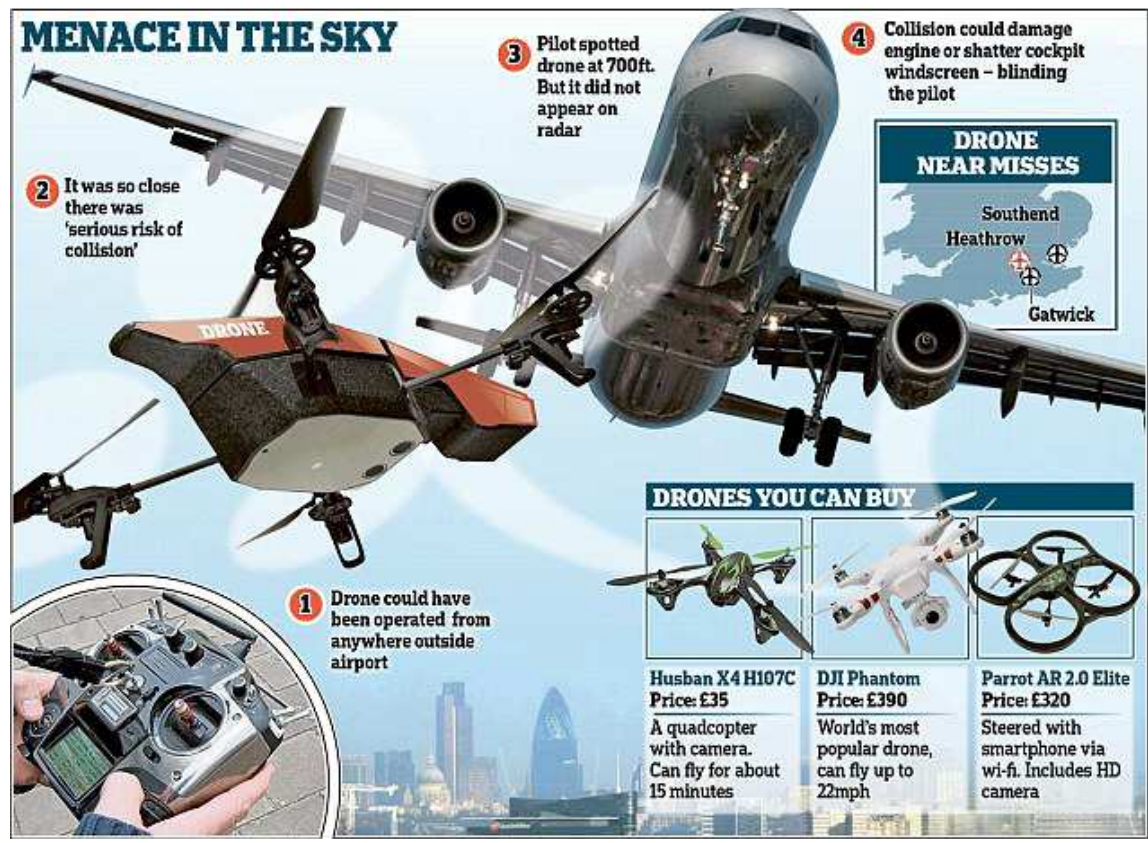

3. A diagram of a dangerous UAV approach to a landing plane near the airport [2]

\section{Possibilities of counteracting the threat from the UAV}

The threat from UAV resulted in the work on the possibility of combating or overpowering it. For several years, worldwide (including Poland), work has been carried out on UAV electronics interference systems, so that it will be forced to interrupt the task [4]. Research is also being carried out to fight unwanted UAVs by their own "hunter" UAVs capable of destroying or disrupting enemy objects.

For example, the Airbus Defense and Space group has developed a system that reduces the risk of unmanned aircraft entering into areas with limited or banned air traffic. The presented system gives the possibility of detecting from a large distance UAV intrusion into critical areas and then interfering with the operation of its onboard systems and location of the UAV operator. The Airbus system allows detecting unwanted UAVs from a distance of $5-10 \mathrm{~km}$ and disrupting communication between the unmanned operator and the operator who drives it on the ground (resulting in loss of control) and disrupting the navigation system (which usually causes the UAV to fall to the ground). Selex ES came out with a similar initiative by proposing the Falcon Shield system. It is supposed to allow not only damage to electronics but sometimes also to take control of the drone. Selex ES also announces the introduction of the possibility of destroying the drone with a strong electromagnetic pulse.

It is worth noting that Polish companies also work on such solutions. For example, SafeSky is a Polish project that is the result of the work of three companies: SIRC, Bioseco and Bonda.pl [6]. The system is able to detect UAVs in the sky that fly illegally. SafeSky for tracking drones uses both video cameras and special radars. Thanks to this, you can follow all flight parameters of a drone or a set of drones live. If necessary, the flying intruder can be intercepted and brought to the ground, or simply directed to the open space and broken down [12]. The program has generated interest from the Government Protection Bureau, which may purchase the Safe Sky system when it is ready. 


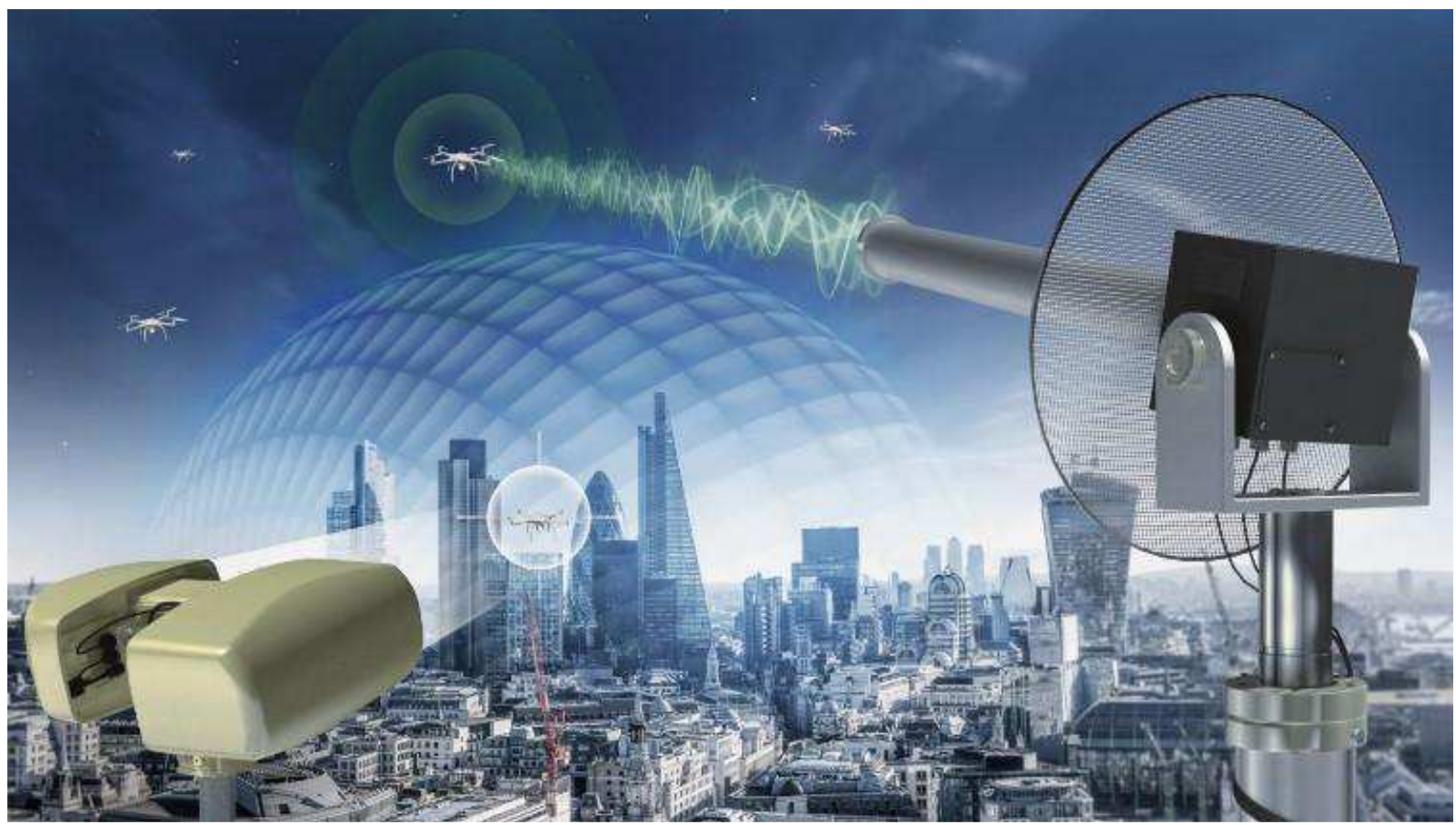

4. Selcon ES Falcon Shield antidrug system [3]

Another example is the Jastrząb system created by the Hertz Systems company from Zielona Góra. The manufacturer states that its detection of drones is $100 \%$. The Jastrząb system can be used stationary as well as on a mobile platform, which allows for a wide range of applications both in the protection of permanent facilities and the protection of mass events. Omnidirectional radar allows monitoring of the area within 360 degrees and within a radius of $3000 \mathrm{~m}$. The system monitors the area in real time, distinguishing between drones from manned aircraft and birds, which completely eliminates the risk of confusion. One of the elements of the system is the neutralizer sending the interfering signal. Jastrząb allows you to cut off communication between the UAV and the operator, which causes its safe to bring to the ground, where it is not a threat. This is extremely important in the case of mass events, during which the downing of UAV could pose an additional threat to the people gathered [16].

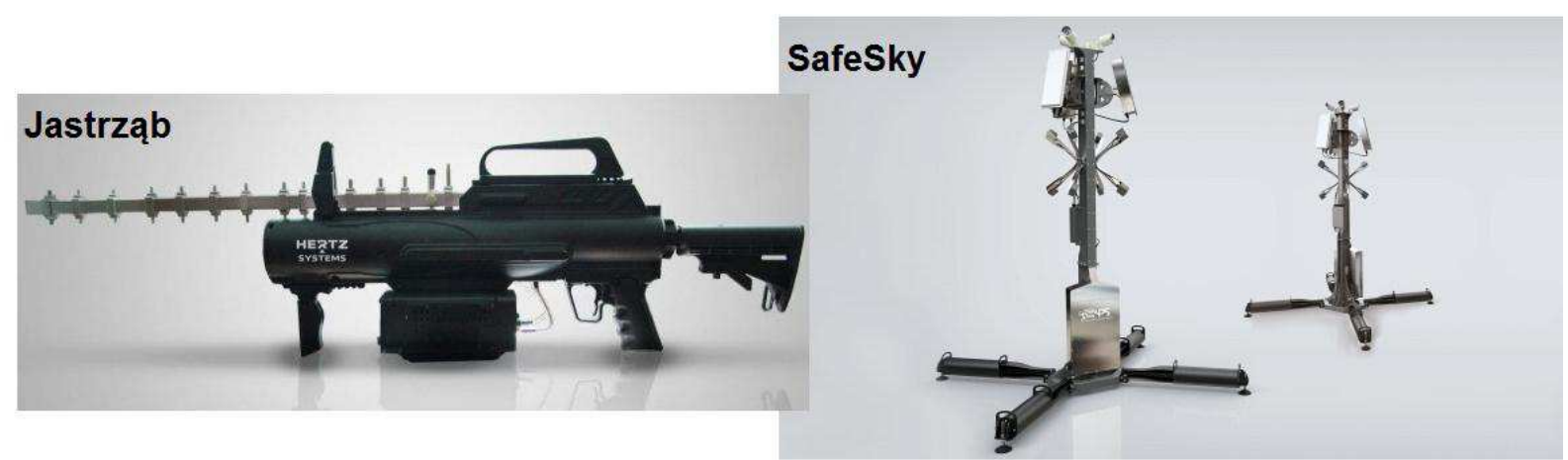

5. Polish antidronic systems Hertz Systems Jastrząb and Advanced Protection Systems SafeSky [17], [5]

\section{Unmanned aerial vehicles in airport security}

Protection of property for many years is carried out by means of personal supervision of officers of uniformed services (or security staff) and by means of technical means. Various types of protections, cameras, and sensors are used for this purpose. These measures in many cases provide a high level of security, however, in recent years, a new type of equipment has 
appeared that can be used to further secure the CI infrastructure (including airports). It's about unmanned aircraft (UAV), colloquially known as drones. In security-related activities, they serve mainly as carriers of sensors and cameras (also infrared and night-vision devices), although there are also works on drones equipped with light weapons, bombers and missiles (UAV already has ISIS and uses them in combat on Iraq and Syria). The possibility of obtaining visual data means that drones are willingly used to control the progress of construction works and evaluate deviations from the projects planned for a specific construction project. Drones with special sensors are used in agriculture (analysis of soil composition and state of arable fields), in wind energy and in construction (inspection of buildings, in particular roofs). Unmanned aerial vehicles equipped with telemetry systems and television or thermal imaging cameras are more and more often used in security systems, among others in the protection of facilities. One UAV is able to patrol the area for which several hundred people would need to be inspected. Thanks to the use of drones, you can both reduce operating costs and increase the effectiveness of patrols.

The German GEMOS from Ela-soft from 2016 can be given as an example of a system that takes into account the use of UAV in object protection. GEMOS has over 750 interfaces for communication with classic security systems: fire protection, burglary and assault signaling, access control systems, video surveillance systems, etc. recently, it is also possible to integrate the GEMOS security system using UAV [1].

The IT system allows determining the route of automatic UAV flight, without the need to manually control the drone. Unmanned aerial vehicles equipped with cameras are here the support of perimeter protection systems. The drone passes a specific route on the border of the guarded zone, at the same time transmitting the picture to the operator. The route is determined by determining any number of turning points. In addition to continuous operations, you can also program cyclical missions, performed from time to time. After completing the route, UAV returns to the base (charging station). The system analyzes the image on an ongoing basis and any anomalies are immediately displayed to the operators. In the event of a crisis situation, the operator can send a drone to a specific location, using the camera to verify the cause of an alarm caused by one of the subsystems. If it turns out that the alarm is not false, the operator will be able to manually control the drone and observe the situation. UAV of the GEMOS system is equipped with a gas concentration meter, a temperature meter or an infrared camera.

Work is also being carried out on drone capable of deterring birds from the airport and capable of intercepting (or destroying) undesirable alien drones. For example, the Japanese police in Tokyo conducts UAV DJI S900 trials equipped with a special net for catching others, drones.

\section{Types of UAVs useful in the protection of airport infrastructure}

Drones for uniformed services and protection are also offered by Polish companies, although they do not yet have such a comprehensive system as GEMOS in their offer. However, the development of such a system by Polish companies seems to be a matter of time. However, when it comes to the aircraft themselves, both Polish and foreign models are available on the market.

As an example of the UAV airframe useful for observation of objects, one can give a Polish Manta plane from Flytronic from Gliwice. It occurs in versions Manta LE and Manta VTOL (vertical takeoff and landing). The modular design of the Manta VTOL aircraft facilitates transport to any place. Ready to start is achieved in about 30 minutes. The technology used ensures fully autonomous take-off and landing, without the need to use airport infrastructure. High-quality video data and telemetry data are transmitted in real time by a digital radio link. Control over the aircraft is carried out by the flight control station. Data 
is accessed from dedicated operator stations, and the multicast solution provides access to data from multiple computers. Manta VTOL is equipped with a hybrid drive. The security standards of the transmitted data are guaranteed by an advanced radio link with a built-in encryption module. Standard equipment can be modified depending on the needs and purpose [11]. The communication system works in the NATO standard in the band C. Manta was probably the second Polish UAV, which obtained civil registration (SP-XFT granted by the Civil Aviation Office on September 15, 2014 - the first was probably UAV MSP Kozioróg from MSP Marcin Szender who received at the Civil Aviation Office, SP-YAAT marks in June 2014).

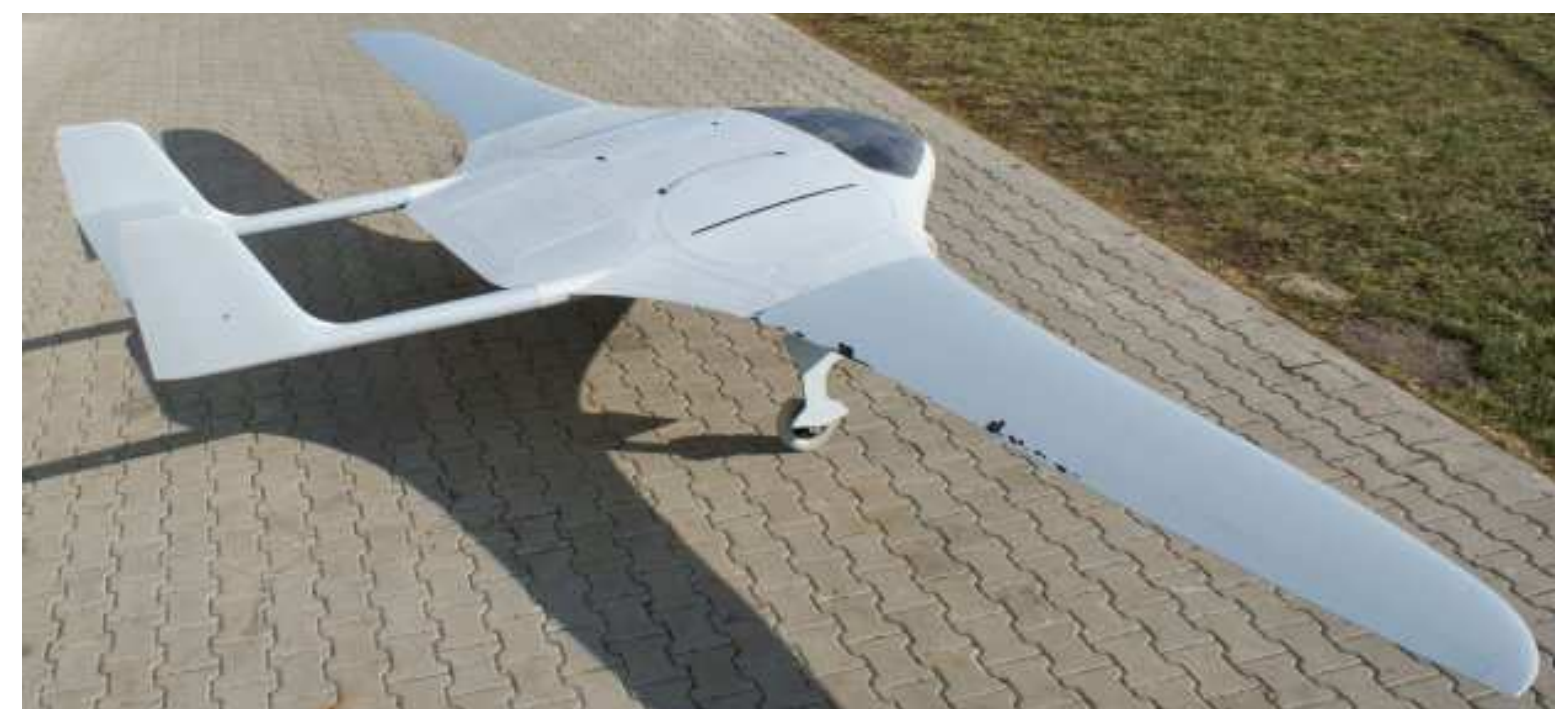

6. An unmanned Manta aircraft from Flytronic [8]

Manta VTOL during vertical take-off and landing launches large vertical fans placed in the panels under the hinged covers. The VTOL capability is very useful in limited terrain but increases weight and limits performance. The Manta LE version weighs $70 \mathrm{~kg}$ (MTOM $140 \mathrm{~kg}$ ), and the VTOL version weighs $75 \mathrm{~kg}$ (MTOM $115 \mathrm{~kg}$ ). LE has a top speed of $160 \mathrm{~km}$ / h, and VTOL $150 \mathrm{~km} / \mathrm{h}$. The spread of Manta's wings is $6.6 \mathrm{~m}$ (LE) and $6.3 \mathrm{~m}$ (VTOL) and $3.3 \mathrm{~m}$ long. The producer states that Manta can carry a number of specialized observation heads: GS3-HD, GS3-IR, GS30 and head Universal HD GS4.

Special observation head GS3 is the proprietary Flytronic solution. GS3-HD is a stabilized single-sensor head, standard equipped with a daylight camera. The head enables observation in the horizontal and vertical plane with the range $\left(\mathrm{N} \times 360^{\circ}\right)$. HD quality images can be transferred to many receivers. The video recording also takes place in the head. GS3HD is characterized by the following features: advanced image stabilization, real-time image transfer to many receivers, human identification from a distance of $5 \mathrm{~km}$, human recognition from a distance of $3.5 \mathrm{~km}$, the ability to read license plates from a distance of $400 \mathrm{~m}$ and optical zoom $30 \mathrm{x}$. 

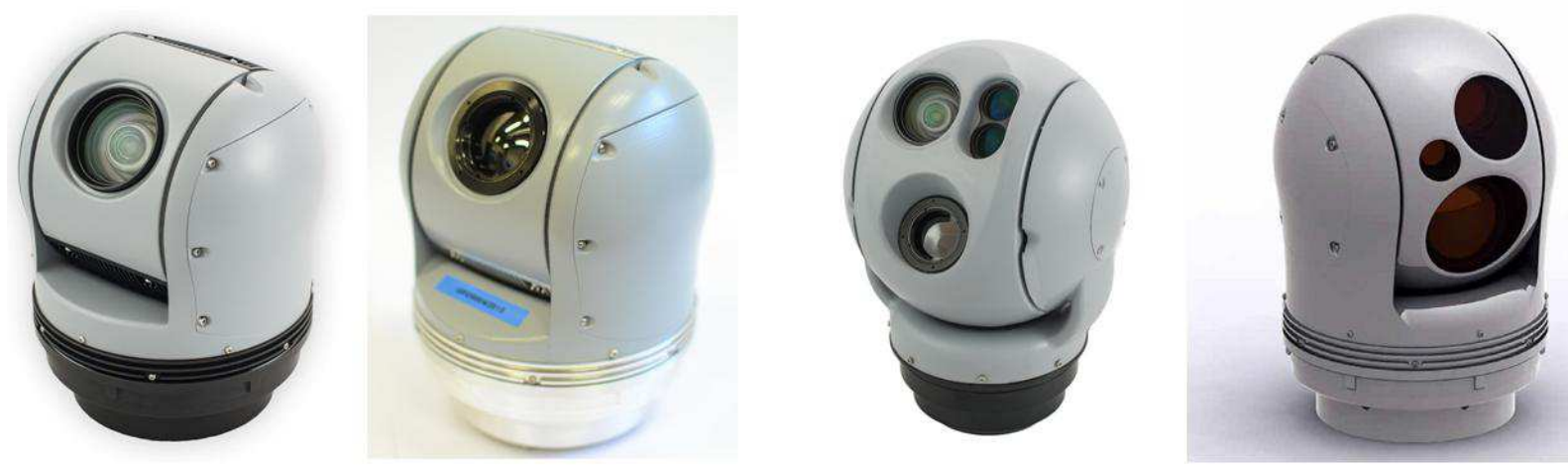

7. The UAV Skytronic Manta observation heads: GS3-HD, GS3-IR, GS30 and HD GS4 [10]

GS3-IR is a stabilized single-sensor observation head, standard equipped with a thermal imaging camera. The head enables observation in the horizontal and vertical plane with the range $\left(\mathrm{N} \times 360^{\circ}\right)$. HD quality images can be transferred to many receivers. Video recording and image processing also take place in the head. Human identification takes place from a distance of $1 \mathrm{~km}$, and human recognition from a distance of $400 \mathrm{~m}$.

The GS30 is a three-sensor stabilized observation head, equipped as standard with a high-resolution daylight camera, a thermal imaging camera, and a laser rangefinder. The head enables observation in the horizontal and vertical plane with the range $\left(\mathrm{N} \mathrm{x} 360^{\circ}\right)$. The image can be transferred to many receivers. The recording of both video streams and image processing takes place on the headboard. The GS30 head is an integral part of the observation system. Other features of the GS30: daylight camera, HD image resolution (expandable to Full HD system), $30 \mathrm{x}$ optical zoom, human detection from a distance of $5 \mathrm{~km}$ and human recognition from a distance of $3 \mathrm{~km}$. G30 has an onboard computer dedicated to image processing on the headboard, LWIR thermal camera, image resolution 640x480 and laser rangefinder.

GS4 is a two-sensor, stabilized observation camera equipped with high-resolution daylight and a thermal imaging camera. The equipment is supplemented by a laser marker. The head enables observation in the horizontal and vertical plane with the range $\left(\mathrm{N} \mathrm{x} 360^{\circ}\right)$. The image can be transferred to many receivers. The recording of both video streams and image processing takes place on the headboard. Main features of GS4: HD quality (optional Full HD), 30x optical zoom, human detection from a distance of $5 \mathrm{~km}$ and human recognition from a distance of $3 \mathrm{~km}[9]$.

In addition to Manta, Flytronic also offers UAV FlyEye, FlySAR, and twin-engine FT-5 Moose, and also manufactures a number of observation heads (including those described above). As you can see, UAV can be very useful when protecting IK. They can, for example, help people and provide observation from heights. A single UAV with the right equipment can track the same area as several hundred people. UAVs seem to be a more and more needed and soon even indispensable means of protecting CI from potential threats (technical failures, attempts of sabotage, etc.). The UAVs of vertical take-off and landing (especially the multirotors) seem particularly useful, but their shortcoming is the short flight time (usually 10-40 min) resulting from the battery capacity. However, the technique goes ahead and one should expect that this problem will be solved within the next decade. Another problem is so far a small social awareness about the suitability of UAV for protection. To this end, information campaigns should be carried out among relevant services, authorities and CI managing bodies. However, it should be emphasized that even the Polish market can already see the first positive practical experience in infrastructure protection. For example, attempts using UAV to 
protect railway routes have been successfully performed by PKP. Surprisingly, on the sections where the railway was supervised by drones, the thefts fell by almost $60 \%$ [21].
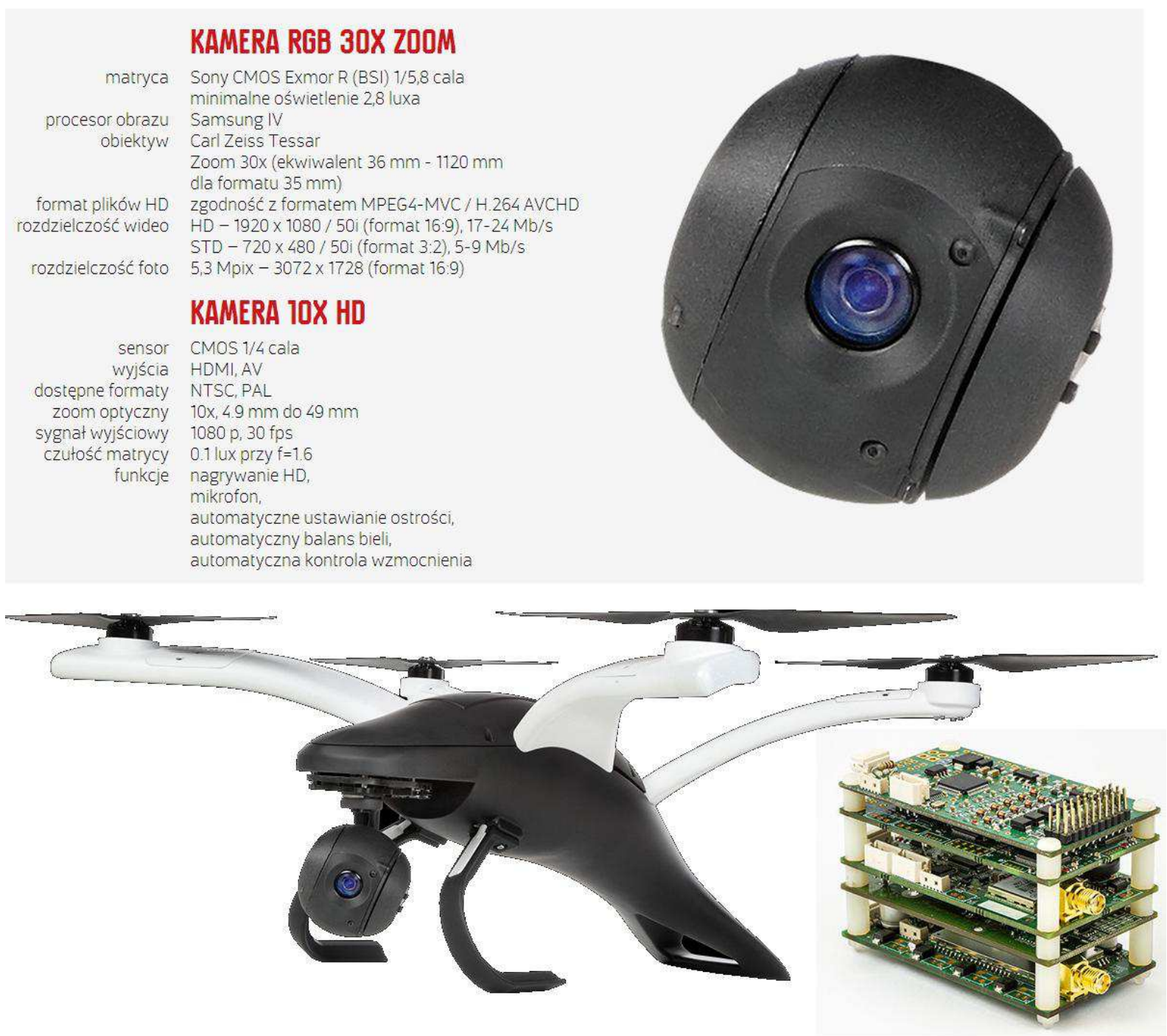

8. Polish UAV Dron House S.A. Bielik with his cameras and the Polish DARTSIL onboard computer including FDR flight recorder [7]

PKP CARGO has previously used the commercial Chinese UAV type DJI Phantom 3 and G4 Eagle V2 of the German company Multirotor Service Drone [18], but recently also purchased Polish UAV Bielik from Dron House SA. from Warsaw (http://www.dronhouse.pl). PKP published Bielik's photos with SP-YDHL registration and optimistic opinions on its use. The producer reports that Bielik has a range of $5 \mathrm{~km}$, an HD (or Full HD) camera, $30 \mathrm{x}$ zoom, a ceiling of $6000 \mathrm{~m}$, operating range at temperatures from $-15^{\circ}$ $\mathrm{C}$ to $+50^{\circ} \mathrm{C}$, flight time $30-50 \mathrm{~min}$, dimensions $80 \mathrm{~cm}$ (length) $\times 72 \mathrm{~cm}$ (width) $\times 30 \mathrm{~cm}$ (height), empty weight $3.5 \mathrm{~kg}$ (without video head) and maximum speed up to $70 \mathrm{~km} / \mathrm{h}$. Bielik has a flight data recorder FDR and can be stabilized by means of satellite navigation (GPS, GLONASS or BEIDOU). Thanks to the system developed by Dron House S.A., full control over the drone with the use of GSM network is possible. The DARTSIL onboard computer was developed by Polish scientists. It is a specialized unmanned and autonomous device, operating in two modes: manual and automatic. Allows an autonomous flight in 
accordance with the mission requirements set by the operator. DARTSIL uses multi-process architecture used by global aviation companies.

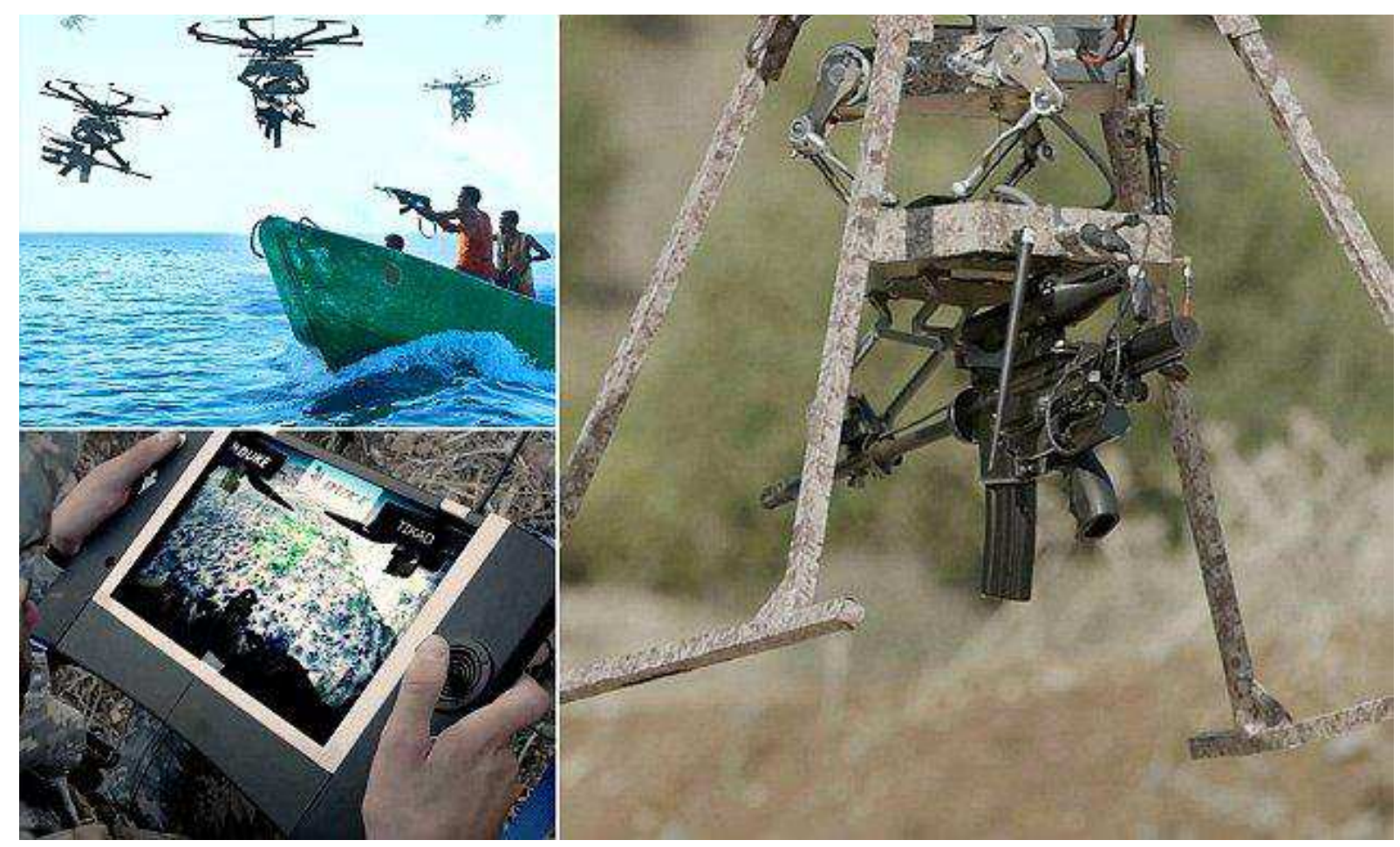

9. American UAV Duke Robotics Inc. TIKAD armed with a machine gun [13]

Until now, the UAV models presented here only offered the transfer of cameras and sensors. It turns out, however, that it is possible to adapt a light drone to carry weapons, both bomb, and shooting. As an example, you can enter the American TIKAD structure from Duke Robotics Inc. TIKAD is a multi-rotor, which on a special suspension can carry various types of rifles and, what's more, shoot them accurately during the flight. TIKAD weighs $50 \mathrm{~kg}$, can carry $13 \mathrm{~kg}$ of weapons, and its operational ceiling reaches $450 \mathrm{~m}$. In 2015, TIKAD passed the tests in Israel.

\section{Summary}

The increase in the volume of light UAVs commonly used causes that they also reach unauthorized hands. We are talking here about irresponsible legal operators who violate the types of airspace prohibited for them, as well as people who want to make an act of unlawful interference against the air traffic. Experience shows that even a light drone can pose a serious threat to airport security. Therefore, appropriate preventive measures should be implemented. The production of means of disturbing or destroying unwanted UAVs seems to be a new growing market that will undoubtedly develop dynamically. In the network, you can find descriptions of many programs involving the construction of miniature missiles, barrel weapons, and even lasers used to destroy the drone. It can be assumed that in 10-20 years this type of equipment may be necessary at IK facilities, especially at airports. This is also important information for Polish producers who should offer and constantly develop their own products in this area. 


\section{Source materials}

[1] Brzuchalska K., Dron jako narzędzie wspomagajace system bezpieczeństwa, w: „Czasopismo Zabezpieczenia” nr 2/2017.

[2] http://www.dailymail.co.uk/sciencetech/article-2864691/Drone-near-miss-scare-700ftHeathrow-airliner.html

[3] http://www.defence24.com/263562,przemysl-zwalcza-nielegalne-drony

[4] http://www.defence24.pl/239815, bezzalogowce-na-celowniku-jak-przeciwdzialaczagrozeniom

[5] http://www.detectdrones.com

[6] http://www.detectdrones.com.

[7] http://www.dronhouse.pl

[8] http://www.flytronic.pl

[9] http://www.flytronic.p1/Dzialalnosc/Oferta/Glowice-obserwacyjne.aspx

[10] http://www.flytronic.p1/Dzialalnosc/Oferta/Glowice-obserwacyjne.aspx

[11] http://www.flytronic.pl/Dzialalnosc/Oferta/Manta-VTOL.aspx

[12] http://www.spidersweb.pl/2015/07/safesky-system-antydronowy-z-polski.html

[13] https://dukeroboticsys.com/invest/

[14] https://isis.liveuamap.com/en/2017/6-february-isis-telegram-channels-sharing-tips-onhow-to

[15] https://www.ar15.com/forums/general/-ARCHIVED-THREAD-ISIS-Drone-Strike-onIraqi-Humvee/5-1969253/\&page $=4$

[16] https://www.hertzsystems.com/product/systemy-antydronowe/

[17] https://www.hertzsystems.com/product/systemy-antydronowe/

[18] https://www.multirotor.net/en/applications/surveillance

[19] Narodowy Program Ochrony Infrastruktury Krytycznej, praca zbiorowa, Rządowe Centrum Bezpieczeństwa, Warszawa 2013, s. 52; http://rcb.gov.pl/wpcontent/uploads/NPOIK-dokument-główny.pdf

[20] Rynek dronów w Polsce 2016. Świt w dolinie śmierci, praca zbiorowa (red. S. Kosieliński), wyd. Instytut Mikromakro, Warszawa 2016

[21] Żuber M., Infrastruktura krytyczna państwa jako obszar potencjalnego oddziaływania terrorystycznego, w: „Rocznik Bezpieczeństwa Międzynarodowego” 2014, vol. 8, nr 2 